\title{
Arquitectura del agua
}

\author{
Arquitectura del agua
}

\author{
Juan Gustavo Cobo Borda
}

coborda@gmail.com

\section{Resumen}

La obra del artista tolimense Germán Botero invita a descubrir el sentido trascendental que reside en la naturaleza. Tanto en sus delicados ensamblajes geométricos como en la arrolladora presencia de los maderos vagabundos que arroja el océano, reside una silenciosa evocación a prácticas ancestrales mágicas de la región andina. En esta edición, Juan Gustavo Cobo explora la fascinante mirada de Botero.

Palabras clave: escultura, arte colombiano, instalación, Germán Botero.

\section{Abstract}

The work of German Botero, an artist from Tolima, Colombia, invites you to discover the transcendental meaning that resides in nature. Both in their delicate geometric assemblies as well as in the overwhelming presence of stray logs that carries the ocean, lies a quiet evocation of ancient magical practices of the Andean region. In this edition, Juan Gustavo Cobo explores the fascinating view of Botero.

Keywords: sculpture, Colombian art, installation, Germán Botero. 


\title{
Arquitectura del agua
}

\section{Arquitectura del agua}

\begin{abstract}
Juan Gustavo Cobo Borda
Poeta y ensayista bogotano. Fue director durante una década (1973-1984) de la revista Eco, de la librería Buchholz, y Gaceta, del Instituto Colombiano de Cultura. Ha ocupado cargos diplomáticos en Buenos Aires y Madrid y fue embajador en Grecia. Miembro número de la Academia Colombiana de la Lengua desde 1993, y correspondiente, de la Academia Española. Ha sido jurado tres veces del Premio Juan Rulfo, (Guadalajara, México); del Rómulo Gallegos, (Caracas); del Reina Sofía de poesía iberoamericana (Madrid) y del Neustad, Universidad de Oklahoma, Estados Unidos. Ha colaborado con otras publicaciones, como Plural, de México, $A B C$, de España, y El Nacional de Venezuela.
\end{abstract}

\section{Introducción}

¿Se puede edificar sobre el agua? Si se hace con algo tan leve y frágil como vidrio, aluminio y madera, si es posible. Así lo ha logrado Germán Botero en esas estructuras flotantes que son jaulas para el viento o maquetas lacustres que a partir de la playa ascienden contra un telón de fondo de edificios o se proyectan sobre un horizonte de aguas en movimiento. Los dos ritmos se entrelazan y contraponen. Dialogan con su pasado de arquitecto, de maquetas de la imaginación, pero a la vez nos traen un futuro imprevisible y humanizado. Las maderas que arroja el mar y que pueden configurar dispuestas por el artista un bosque en una plaza, en una mezcla admirable de tosquedad y refinamiento. De disposición circular, como un reloj de siglos, o de simple ave, cuerpo tendido o animal prehistórico, pulido pero sin embargo aún dispuesta a expandirse, cuando se disponen en la sala de la galería o en medio del salón de un club. 


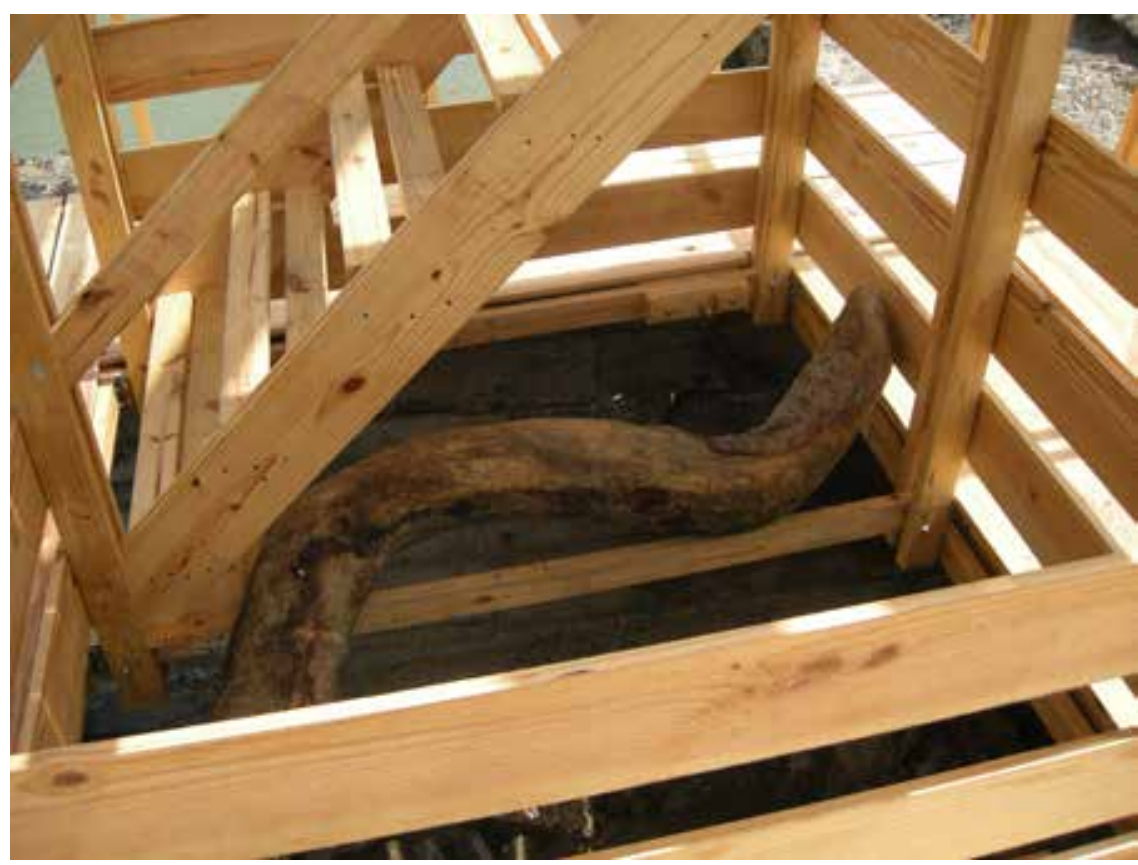

Palafito Panamá (detalle)

Qué energía y qué elocuencia en esos troncos abandonados que sólo cuatro o cinco pescadores alcanzan a mover y cuya monumentalidad acentúa su entronque con una naturaleza primordial de medusas pétreas. De orígenes milenarios, como esas casas hechas sobre palafitos donde la ciénaga las lame todo el día pero tienen también en su base un corral arenoso para animales y que jueguen los niños y el sueño desmesurado no descarta una cancha de fútbol al unir varias de ellas.
Qué pirámides y qué terrazas se levantan con el pensamiento concreto que recicla y a la vez respeta el agua, tiene algo de gratuita fantasía pero a la vez va disponiendo sobre la arena la huella de un Robinson Crusoe que sabe conjugar lo imprevisto con el ritual, lo desechado con la renovada consagración de los elementos primordiales que pudiéramos decir ya estaban antes de la creación misma.

Por ello, quizás, Germán Botero, en esa nueva arqueología se tiende sobre esos troncos para ser el 
enlace entre tiempo y eternidad. Entre la indiferencia natural con que la incesante respiración de las olas derriba las ciudades del hombre y sólo dejar las señalas con que el ojo del artista rescata y dispone tantos naufragiao, tantas ambiciones que la arena pule y desgasta hasta sólo convertirlas en maderas, carreto o nazareno, coro Maracay, que nos incitan a mirar y sobre todo a palpar y acariciar.
Esas semillas son el nuevo alfabeto de una recobrada sensibilidad.

Con el título Palabras de madera, editado por Jaime Vargas, ha aparecido en el 2013 un libro sobre Germán Botero con textos de Santiago Aristizábal, Roberto Burgos Cantor, Juan Manuel Roca, William Ospina y Santiago Mutis Durán.

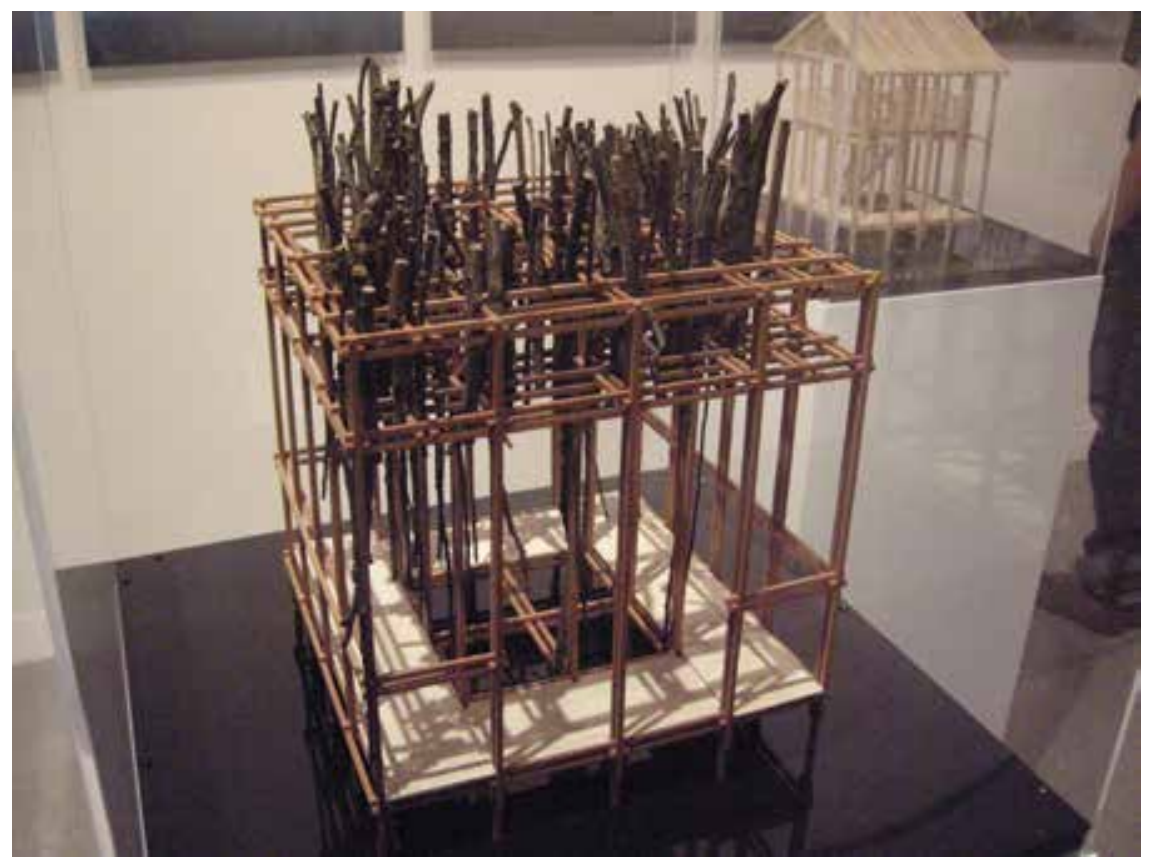

Maqueta Lacustre 


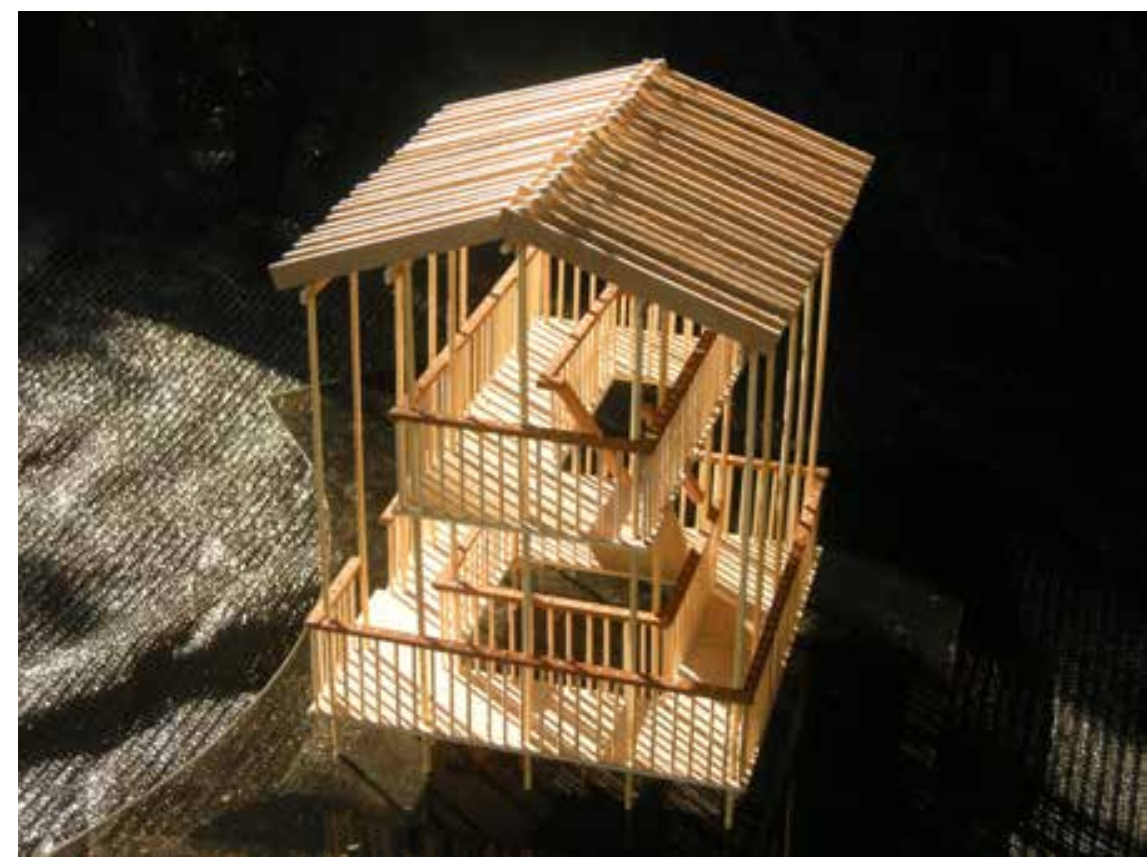

Maqueta Palafito, Panamá

\section{Espacio de Botero}

Botero nació en Fresno (Tolima) en 1946. Estudió arquitectura en la Universidad Nacional de Colombia y fue fundador de la carrera de Diseño Industrial de la Universidad Pontificia Bolivariana de Medellín en 1972. Esta experiencia marcó y definió el tipo de abstracción que manejó durante largo tiempo. En 1974 recibió el primer premio de escultura en el XXVI Salón de Artes Visuales por la obra Torre en Metal. Ha dirigido buena parte de su esfuerzo a la realización de obras de grandes dimensiones en el espacio público. México, Cuba, Puerto Rico, Venezuela, Argentina, Corea, China y Colombia son algunos de los países que le han encargado obras por contratos que ganó en concursos internacionales.

Publicación eltiempo.com

Sección: Cultura y entretenimiento

Fecha de publicación 2 de noviembre de 2007 